\title{
A Robust Extended Kalman Filter for Speed-Sensorless Control of a Linearized and Decoupled PMSM Drive
}

\author{
P. Tety ${ }^{1}$, A. Konaté ${ }^{2}$, Olivier Asseu2 ${ }^{2}$, E. Soro² ${ }^{2}$ P. Yoboué2 , A. R. Kouadjo² \\ ${ }^{1}$ Institut National Polytechnique Houphouët Boigny (INPHB), Yamoussoukro, Côte d'Ivoire \\ ${ }^{2}$ Ecole Supérieure Africaine des Technologies de I'Information et de la Communication (ESATIC), Abidjan, Côte \\ d'Ivoire \\ Email: tety@nic.ci, adama.konate@esatic.ci, \\ pamela.yoboue@esatic.ci, ranok80@yahoo.fr
}

Received 22 August 2015; accepted 27 October 2015; published 30 October 2015

Copyright (C) 2015 by authors and Scientific Research Publishing Inc.

This work is licensed under the Creative Commons Attribution International License (CC BY).

http://creativecommons.org/licenses/by/4.0/

(c) (i) Open Access

\section{Abstract}

This paper uses a robust feedback linearization strategy in order to assure a good dynamic performance, stability and a decoupling of the currents for Permanent Magnet Synchronous Motor (PMSM) in a rotating reference frame $(d, q)$. However this control requires the knowledge of certain variables (speed, torque, position) that are difficult to access or its sensors require the additional mounting space, reduce the reliability in harsh environments and increase the cost of motor. And also a stator resistance variation can induce a performance degradation of the system. Thus a sixth-order Discrete-time Extended Kalman Filter approach is proposed for on-line estimation of speed, rotor position, load torque and stator resistance in a PMSM. The interesting simulations results obtained on a PMSM subjected to the load disturbance show very well the effectiveness and good performance of the proposed nonlinear feedback control and Extended Kalman Filter algorithm for the estimation in the presence of parameter variation and measurement noise.

\section{Keywords}

Robust Feedback Control, PMSM, Extended Kalman Filter, Estimation

\section{Introduction}

In recent years, there has been an emerging growth of PMSM. This machine has been widely used in many in-

\footnotetext{
"Corresponding author.
}

How to cite this paper: Tety, P., Konaté, A., Asseu, O., Soro, E., Yoboué, P. and Kouadjo, A.R. (2015) A Robust Extended Kalman Filter for Speed-Sensorless Control of a Linearized and Decoupled PMSM Drive. Engineering, 7, 691-699. 
dustrial applications. The main advantages, as compared with other AC motor drive, are high power factor, high power density, high torque to current ratio, high efficiency, Hence robustness, lower loss, lower maintenance and less complex motor can be obtained [1] [2].

However, the control of PMSM is proved very difficult because the dynamic model of the PMSM is nonlinear, multidimensional and complex where some parameters vary with temperature or saturation. This nonlinear dynamic behavior induces the use of nonlinear feedback control strategy [3] [4] in order to permit a decoupling of the PMSM variables in a $(d, q)$ coordinate so that stator currents can be separately controlled.

On the other hand, to preserve and improve the reliability under parameters variation and noises injected by the inverter (which can induce a state-space "coupling" and degradation of the system), a robust control approach has been made on the motor drives [5]-[7]. This control algorithm uses $\mathrm{H}$-infinity synthesis of currents correctors in order to insure robust stability and performances of the inner current loop.

To guarantee good performances in presence of parameters variations (more specifically the stator resistance and load variation) and whereas advanced PMSM control strategies require knowledge of the instantaneous speed (which is difficult to access), the technique based on the state observer allowing an on-line estimation of the speed, position, load torque and the stator resistance is necessary.

Accurate estimation of speed in the presence of measurement and system noise, and parameter variations is a challenging task. Kalman filter (KF) named after Rudolph E. Kalman [8] is one of the most well known and often used tools for stochastic estimation. The KF is essentially a set of mathematical equations [9] [10] that implement a predictor-corrector type estimator that is optimal in the sense that it minimizes the estimated error covariance when some presumed conditions are met. For the speed, torque and stator resistance estimation problem of PMSM, where parameter variation and measurement noise is present, KF is the ideal one.

Many literatures on the KF technique and its applications, essentially extended for the estimation of the speed, have been published [11]-[13]. However, using the nonlinear feedback control, this Extended KF (EKF) technique doesn't take into account the combination load torque and stator resistance variation.

In the present research, after a brief review of the PMSM model, on the one hand a robust Input-output linearization and decoupling scheme is developed and on the other hand a sixth-order discrete-time EKF, based on KF principle, is proposed to estimate the speed, currents, position and extended for the load torque and stator resistance reconstruction.

Finally, the proposed combination nonlinear feedback control and EKF approach are confirmed by simulations results carried out on PMSM drive system in the presence of measurement noise and parameter variations.

\section{PMSM Equations and Robust Feedback Control}

By assuming that the saturation of the magnetic parts and the hysteresis phenomenon are neglected; by considering the case of a smooth-air-gap PMSM (where the inductances are equal: $L_{d}=L_{q}$ ) and according to the field oriented principle where the direct axis current $\left(I_{d}\right)$ is always forced to be zero which simplifies the dynamics and achieve maximum electromagnetic torque per ampere, the PMSM model in the rotor reference $(d, q)$ frame are as follows [2] [5]:

$$
\left\{\begin{array}{l}
\dot{X}=F(X)+G \cdot U \\
Y=H(X)=\left[\begin{array}{ll}
h_{1}(X) & h_{2}(X)
\end{array}\right]^{\mathrm{T}}=\left[\begin{array}{ll}
I_{d} & I_{q}
\end{array}\right]^{\mathrm{T}}
\end{array}\right.
$$

with $X=\left[I_{d} I_{q} \Omega \theta\right]^{\mathrm{T}}, \quad U=\left[V_{d} V_{q}\right]^{\mathrm{T}}$

$$
F(X)=\left[\begin{array}{l}
f_{1}(X) \\
f_{2}(X) \\
f_{3}(X) \\
f_{4}(X)
\end{array}\right]=\left[\begin{array}{l}
-\frac{R_{s}}{L_{d}} I_{d}+\frac{L_{q}}{L_{d}} p \cdot I_{q} \cdot \Omega \\
-\frac{R_{s}}{L_{q}} I_{q}-\frac{L_{d}}{L_{q}} p \cdot I_{d} \cdot \Omega-\frac{p \cdot \Phi_{f}}{L_{q}} \Omega \\
-\frac{f}{J} \cdot \Omega+\frac{p \cdot \Phi_{f}}{J} I_{q}-\frac{T_{L}}{J} \\
p \cdot \Omega
\end{array}\right] ; \quad G=\left[\begin{array}{cc}
\frac{1}{L_{d}} & 0 \\
0 & \frac{1}{L_{q}} \\
0 & 0 \\
0 & 0
\end{array}\right]=\left[\begin{array}{cc}
g_{1} & 0 \\
0 & g_{2} \\
0 & 0 \\
0 & 0
\end{array}\right]
$$


This Equation (1) shows that the dynamic model of PMSM is nonlinear because of the coupling between the electrical currents and some parameters (in particular $R_{s}$ ) vary with temperature. Thus, in order to control independently the currents $\left(I_{d}, I_{q}\right)$ and then preserve the robustness performance and stability of the system under parameters variation and measurement noise, we can uses a robust feedback linearization strategy to regulate the motor states [18]. Thus, we can see that the system (1) has relative degree $r_{1}=r_{2}=1$ and can be transformed into a linear and controllable system by chosen:

- a suitable and an appropriate change of coordinates given by:

$$
z_{1}=h_{1}(x) ; z_{2}=h_{2}(x) \text { with }
$$

where $\left[v_{1}, v_{2}\right] T$ are the new input vector of the obtained decoupled systems

- the feedback linearization control having the following form:

$$
u=\left[\begin{array}{cc}
L_{g} h_{1}(x) & 0 \\
0 & L_{g} h_{2}(x)
\end{array}\right]^{-1} \cdot\left[\begin{array}{c}
v_{1}-L_{f} h_{1}(x) \\
v_{2}-L_{f} h_{2}(x)
\end{array}\right]=\left[\begin{array}{cc}
\frac{1}{L_{q}} & 0 \\
0 & \frac{1}{L_{d}}
\end{array}\right]^{-1}\left[\begin{array}{c}
v_{1}-f_{1} \\
v_{2}-f_{2}
\end{array}\right]
$$

This feedback control (3) is effective and leads the system (1) to two decoupled subsystems;

- and two robust controllers $C(s)$, using $H \infty$ synthesis and "Doyle method" [6] [14], defined as:

$$
C(s)=\frac{J(s) \cdot H(s)^{-1}}{1-J(s)} \text { with } J(s)=\frac{1}{\left(1+t_{0} s\right)^{2}} \text { and } H(s)=\frac{1}{1+T s}
$$

The real $t_{0}$ is an adjusting positive parameter, chosen adequately small $\left(t_{0}<1\right)$, in order to satisfy the robustness performance, to have a good regulation and convergence of the currents.

The block diagram structure for the control of $\left(I_{d}, I_{q}\right)$ can be summarized as follows in Figure 1.

However the control of a PMSM generally required the knowledge of the instantaneous speed of the rotor that is not measurable. Also a variation of the stator resistance or/and load torque $\left(R_{S}\right.$ and $\left.T_{L}\right)$ can induce a lack of field orientation. In order to achieve better dynamic performance, an on-line estimation of rotor speed, stator resistance and load torque is necessary.

In this study, in order to respect to the parametric variations in the presence of measurement and system noise (stochastic estimation), an EKF's algorithm for speed estimation extended for the stator resistance and load torque reconstruction, is presented and explained in the next section.

\section{Model of Extended Kalman Filter}

For parameter estimation using a full order EKF, the model structure (1) is discretized directly using Euler approximation (1st order) proposed in [15]. Furthermore, the state vector is extended to the stator resistance and load torque. Thus, choosing the currents $\left(I_{d}, I_{q}\right)$, speed $(\Omega)$, rotor position $(\theta)$, load torque $\left(T_{L}\right)$ and stator resistance $\left(R_{s}\right)$ as state variables, the voltages $\left(V_{d}, V_{q}\right)$ as inputs, the new discrete-time and Stochastic sixth-order nonlinear dynamic model for the PMSM is described by Equation (5):

$$
\left\{\begin{array}{l}
X_{e}(k+1)=f\left(X_{e}(k), U(k)\right)+n(k)=X_{e}(k)+T_{e} \cdot Q\left(x_{e}(k), U(k)\right)+n(k) \\
Y_{e}(k)=h\left(X_{e}(k)\right)+r(k)
\end{array}\right.
$$

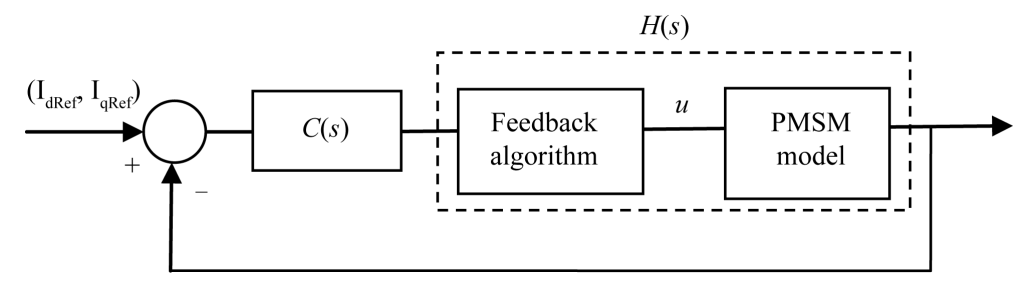

Figure 1. Proposed currents control scheme. 
where $X_{e}(k)=\left[I_{d}(k) I_{q}(k) \Omega(k) q(k) T_{L}(k) R_{s}(k)\right]^{\mathrm{T}}, \quad U(k)=\left[V_{d}(k) V_{q}(k)\right]^{\mathrm{T}}$

$$
\left.\begin{array}{l}
Q\left(X_{e}(k), U(k)\right)=\left[\begin{array}{l}
-\frac{R_{s}(k)}{L_{d}} I_{d}(k)+\frac{L_{q}}{L_{d}} p \cdot I_{q}(k) \cdot \Omega(k)+\frac{1}{L_{d}} V_{d} \\
-\frac{R_{s}(k)}{L_{q}} I_{q}(k)-\frac{L_{d}}{L_{q}} p \cdot I_{d}(k) \cdot \Omega(k)-\frac{p \cdot \Phi_{f}}{L_{q}} \Omega(k)+\frac{1}{L_{q}} V_{q} \\
-\frac{f}{J} \cdot \Omega(k)+\frac{p \cdot \Phi_{f}}{J} I_{q}(k)-\frac{T_{L}(k)}{J} \\
p \cdot \Omega(k) \\
0 \\
0
\end{array}\right. \\
Y_{e}(k)=\left(\begin{array}{l}
I_{d} \\
I_{q}
\end{array}\right)=h\left(X_{e}(k)\right)=\left[\begin{array}{llllll}
1 & 0 & 0 & 0 & 0 & 0 \\
0 & 1 & 0 & 0 & 0 & 0
\end{array}\right] \cdot X_{e}(k)=H \cdot X_{e}(k)
\end{array}\right]
$$

The resulting output vector $Y_{e}(k)$ consists of the estimated motor current in a rotor reference frame being compared to the measured current. The difference is used to correct the state vector of the system model.

$X_{e}(k)$ and $Y_{e}(k)$ are the state vector and output, respectively at the $k$-th sampling instant, i.e. $t=k \cdot T_{e}$ with $T_{e}$ the adequate sampling period chosen without failing the stability and the accuracy of the discrete-time model.

The random disturbance input, represented by $n(k)$, is the sum of modeling uncertainty, the discretization errors and the system noise. The measurement noise is represented by $r(k)$. Both $n(k)$ and $r(k)$, are assumed to be white Gaussian noise with zero mean and covariance matrix $Q$ and $R$ respectively. Consider that:

- $\hat{X}_{e}(k)=$ the estimate of $X_{e}(k)$ and $K(k+1)=$ EKF gain;

- $\hat{X}_{e}(k+1 \mid k)=$ the linear minimum mean square estimate of $X_{e}(k+1)$;

- $P(k+1 \mid k)=$ state prediction covariance error;

- $P(k+1 \mid k+1)=$ state estimation covariance error;

- Initialization givens: $\hat{X}_{e}(0 \mid 0)=\hat{X}_{e}(0)$ and $P(0 \mid 0)=P(0)$.

The steps of the proposed sixth-order Discrete-time Extended Kalman Filter algorithm are as follows:

$$
\left\{\begin{array}{l}
\text { 1) } \hat{X}_{e}(k+1 \mid k)=f\left(\hat{X}_{e}(k \mid k), U(k)\right) \\
\text { 2) } F(k)=\left.\frac{\partial f(\hat{X}(k), U(k))}{\partial \hat{X}(k)}\right|_{X_{e}(k)=X_{e}(k \mid k)} \\
\text { 3) } P(k+1 \mid k)=F(k) \cdot P(k \mid k) \cdot F^{T}(k)+Q \\
\text { 4) } K(k+1)=P(k+1 \mid k) \cdot H^{T}\left[H \cdot P(k+1 \mid k) \cdot H^{T}+R\right]^{-1} \\
\text { 5) } \Delta Y_{e}(k+1 \mid k)=Y_{e}(k+1)-H \cdot \hat{X}_{e}(k+1 \mid k) \\
\text { 6) } \hat{X}_{e}(k+1 \mid k+1)=\hat{X}_{e}(k+1 \mid k)+K(k+1) \cdot \Delta Y_{e}(k+1 \mid k) \\
\text { 7) } P(k+1 \mid k+1)=[I-K(k+1) \cdot H] \cdot P(k+1 \mid k) \\
\text { 8) Increment } k \text { and Go to step } 1
\end{array}\right.
$$

The EKF algorithm consists of repeated use of step (1-8) for each measurement. $F(k)$ is the Jacobian matrix of partial derivatives of $f(\cdot)$ with respect to $X_{e}(k)$. From Equation (5), we obtain: 


$$
F(k)=\left[\begin{array}{llllll}
1 & 0 & 0 & 0 & 0 & 0 \\
0 & 1 & 0 & 0 & 0 & 0 \\
0 & 0 & 1 & 0 & 0 & 0 \\
0 & 0 & 0 & 1 & 0 & 0 \\
0 & 0 & 0 & 0 & 1 & 0 \\
0 & 0 & 0 & 0 & 0 & 1
\end{array}\right]+T_{e} \cdot\left[\begin{array}{l}
-\frac{R_{s}(k)}{L_{d}}+p \cdot \Omega(k)+p \cdot I_{q}(k)-\frac{I_{d}(k)}{L_{d}}+\frac{1}{L_{d}} V_{d} \\
-\frac{R_{s}(k)}{L_{q}}-p \cdot \Omega(k)-p \cdot I_{d}(k)-\frac{p \cdot \Phi_{f}}{L_{q}}-\frac{I_{q}(k)}{L_{q}}+\frac{1}{L_{q}} V_{q} \\
-\frac{f}{J}+\frac{p \cdot \Phi_{f}}{J}-\frac{1}{J} \\
p \\
0 \\
0
\end{array}\right]
$$

\section{Simulation Results and Discussion}

The proposed robust nonlinear feedback control combined with a EKF strategy has been investigated with simulation tests carried out for a $1.6 \mathrm{~kW}$ PMSM by means of SIMULINK in order to illustrate its effectiveness against load, measurement noise and parameter variation (Figure 2). The nominal parameters of the PMSM, determined by means of the least-squares identification techniques proposed by the references [16] [17], are shown in the Table 1.

In order to evaluate its robustness and effectiveness, the comparisons between the estimated state variables and the simulated ones have been realized for several operating conditions with the presence of about $15 \%$ white noise on the measured currents and with additional load torque $\left(T_{l}>1 \mathrm{~N} \cdot \mathrm{m}\right)$.

Thus the simulations are obtained at first in the nominal case with the parameters of the PMSM (Table 1) and then in the second case, with $50 \%$ variation of the nominal stator resistance $\left(R_{s}=1.5 R_{s n}\right)$ in order to verify the behavior of the proposed EFK algorithm estimator with respect to stator resistance and load torque variation.

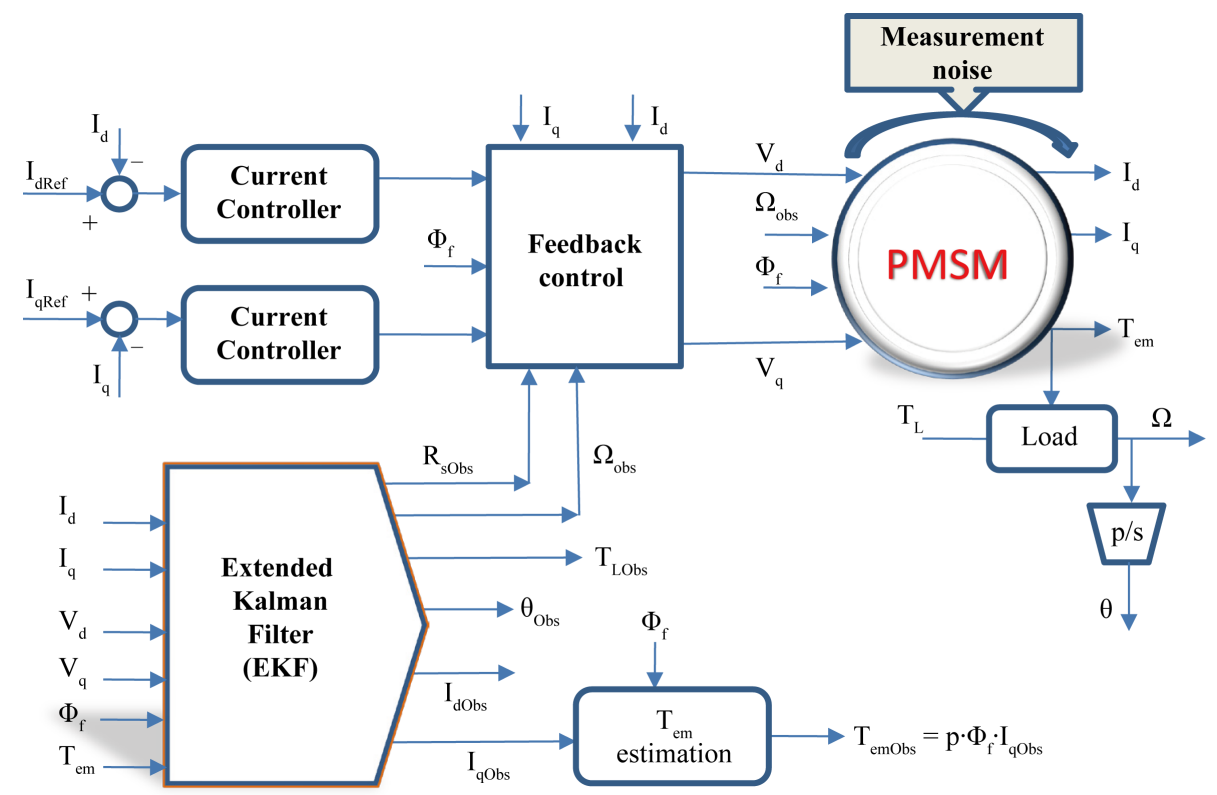

Figure 2. Simulation scheme.

Table 1. Nominal parameters of the PMSM.

\begin{tabular}{ccc}
\hline$P_{m n}=1.6 \mathrm{~kW}$ & $U_{n}=220 / 380 \mathrm{~V}$ & $f_{n}=0.0162 \mathrm{~N} \cdot \mathrm{m} \cdot \mathrm{sec} \cdot \mathrm{rad}^{-1}$ \\
$p=3$ & $\Omega_{\mathrm{n}}=1000 \mathrm{rpm}$ & $J_{n}=0.0049 \mathrm{~kg} \cdot \mathrm{m}^{2}$ \\
$R_{s n}=2.06 \Omega$ & $P h i f_{n}=0.29 \mathrm{~Wb}$ & $L_{q n}=L_{d n}=9.15 \mathrm{mH}$ \\
\hline
\end{tabular}




\section{Initialization and Tuning of the EKF Algorithms}

The important and difficult part in the design of the full order EKF is choosing the proper values for the covariance matrices $Q$ and $R$. The change of values of covariance matrices affects both the dynamic and steady-state.

In order to have a good performance, to insure better stability, convergence time and considerable rapidity of the EKF, the chosen values for the covariance matrices $Q, R$ and $P$ can be initialized and adjusted as follows:

$$
P_{6 \times 6}(0)=\operatorname{diag}\left\{10^{4}\right\} ; R_{2 \times 2}=\operatorname{diag}\left\{10^{3}\right\} ; Q_{6 \times 6}=\operatorname{diag}\{q\},
$$

the real $q_{i}$ must be tuned adequately small: $q \in\left[\begin{array}{ll}0 & 10^{-2}\end{array}\right]$,

Our proposed Feedback control and EKF algorithm operate with a sampling period $T_{e}=1 \mathrm{~ms}$ and using Euler approximation.

Experiment simulation were performed and examined with regards to the following tasks: possibility current changing and load torque acting.

Figure 3 and Figure 4 show the responses of the currents, speed, rotor position, load torque and stator resistance for a step variation of the current reference (IdRef) under noisy conditions.

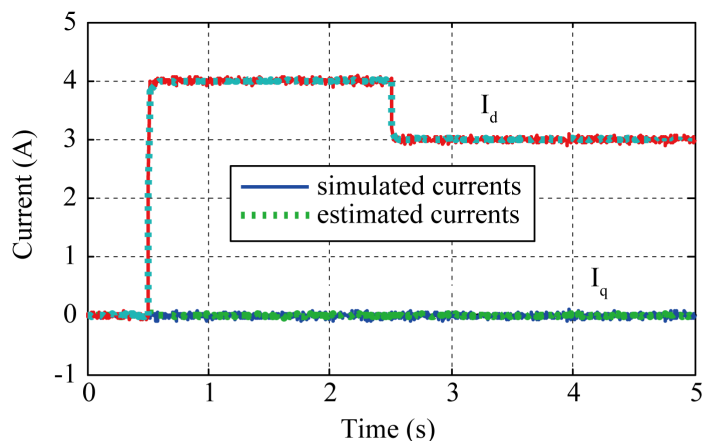

(a)

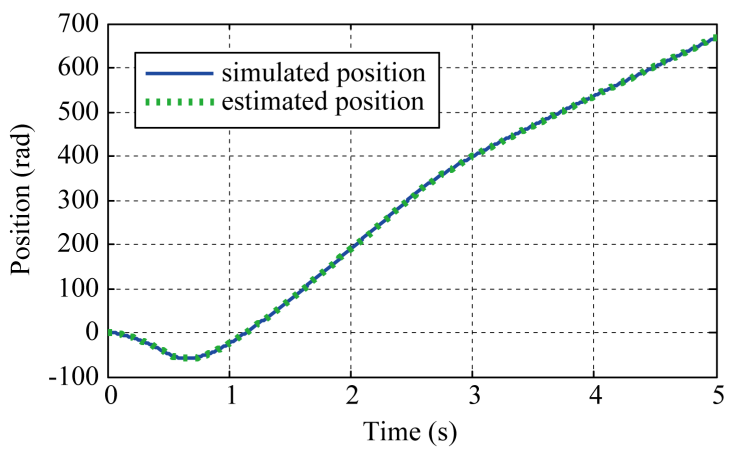

(c)

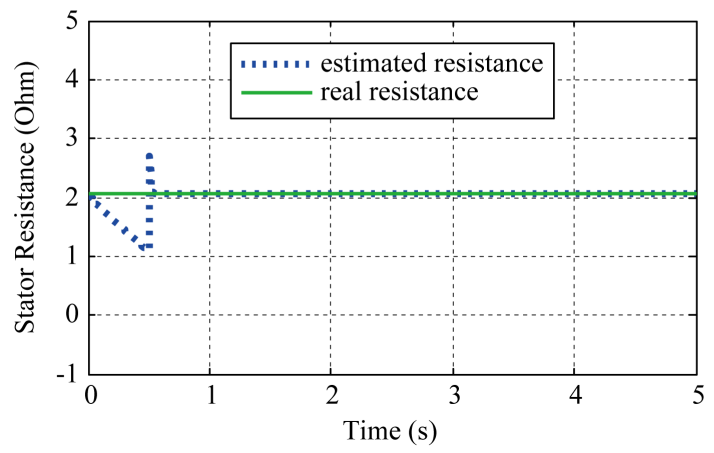

(e)

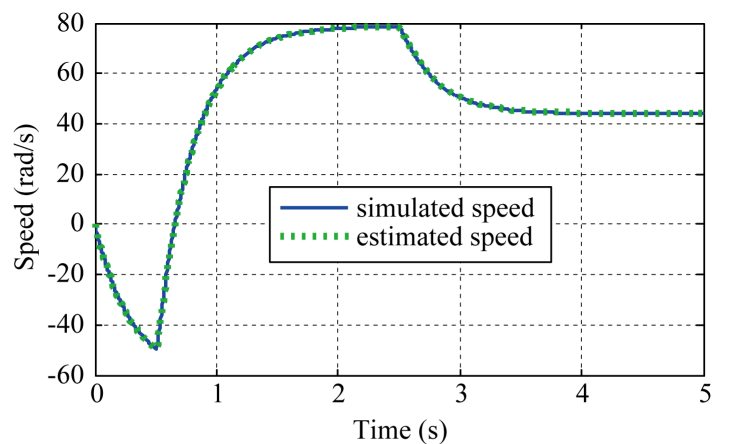

(b)

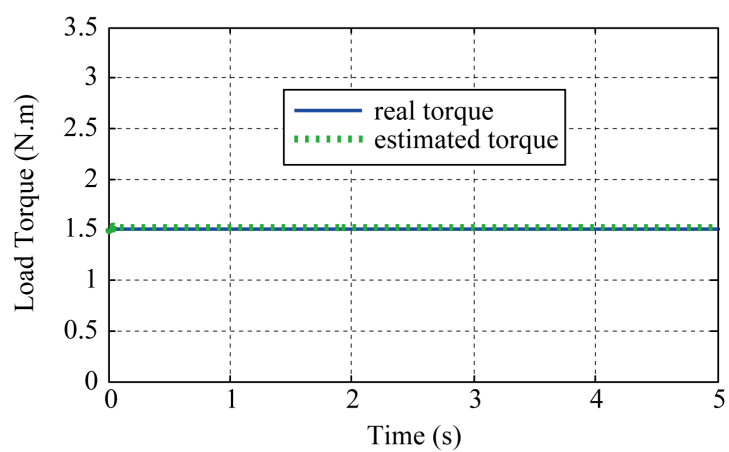

(d)

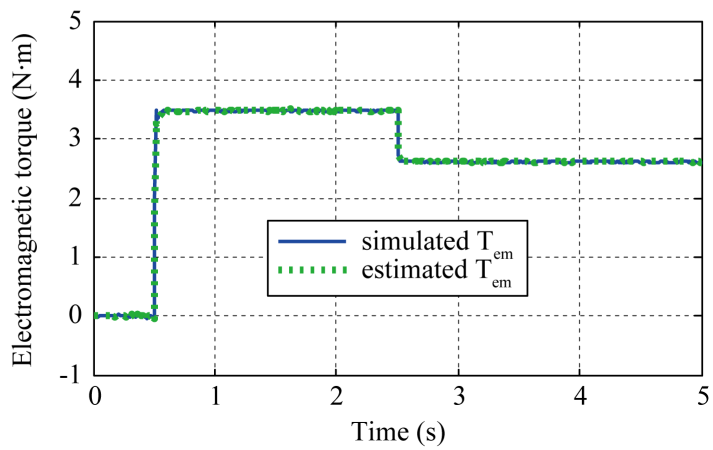

(f)

Figure 3. Nominal case $\left(R_{r}=R_{r n}\right)$ : Comparison between estimated and simulated values for $T_{L}=1.5 \mathrm{~N} \cdot \mathrm{m}$ in the presence of measurement noises. 


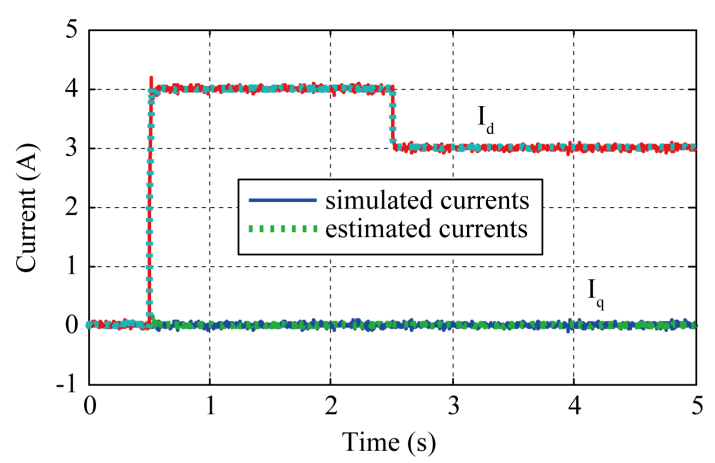

(a)

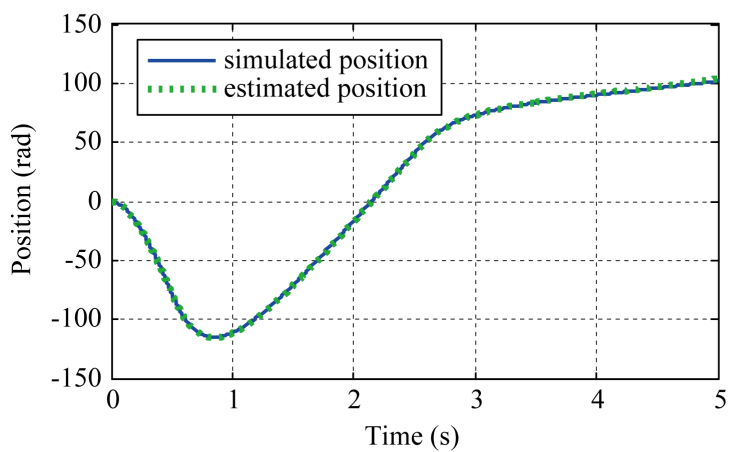

(c)

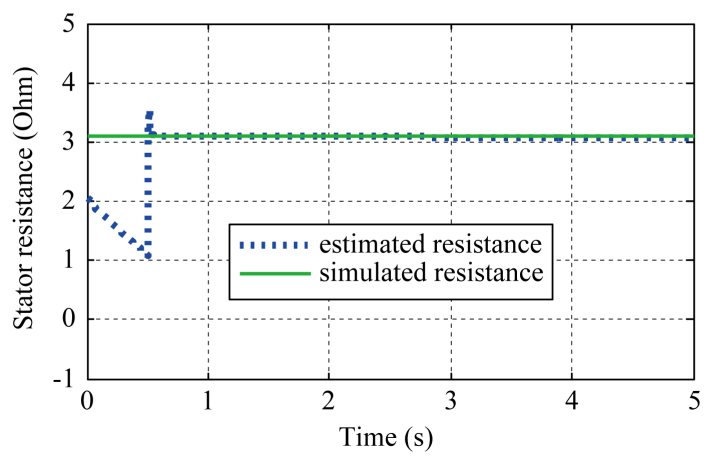

(e)

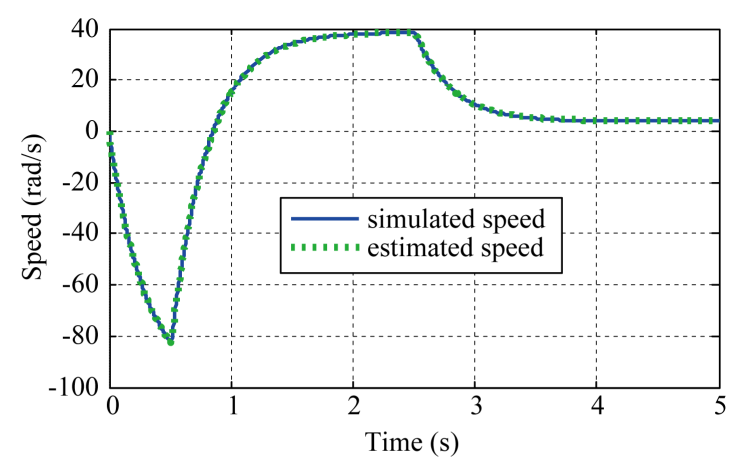

(b)

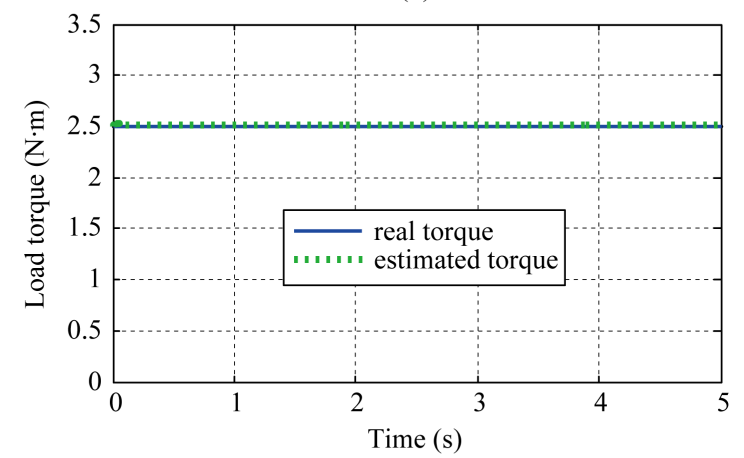

(d)

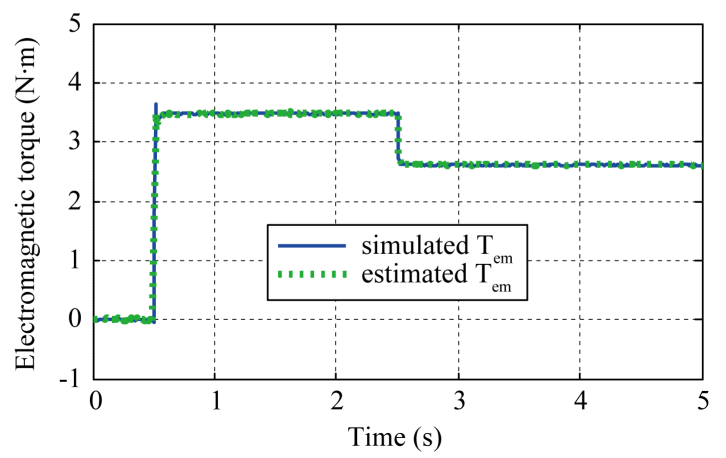

(f)

Figure 4. Non nominal case $\left(R_{r}=1.5 * R_{r n}\right)$ : Comparison between estimated and simulated values for $T_{L}=2.5 \mathrm{~N} \cdot \mathrm{m}$ in the presence of measurement noises.

One can see that in both nominal (Figure 3) and non-nominal cases (Figure 4 where $R_{r}=1.5$ Rrn), the estimated values of currents, speed, rotor position and load torque converge very well to their simulated values and are not affected too much from the injected noise.

The observed better speed responses (Figure 3(b), Figure 4(b)), in the presence of parameter uncertainty and measurement noises, indicate the good regulation and convergence of the currents (with a decoupled system) due to a favorable stator resistance (Figure 3(e), Figure 4(e)) and load torque estimation (Figure 3(d), Figure 4(d)).

These good waveforms illustrate the fast convergence and high performance of the robust decoupling control and EKF algorithm against modeling uncertainty, parametric variation and measurement noise.

\section{Conclusions}

We have shown in this work that a robust nonlinear feedback control combined with a EKF approach have been realized to permit a linearization, decoupling and regulation of the PMSM states (currents) in order to assure a good dynamic performance of the global system and for solving range of problems in sensorless (speed, rotor 
position and load torque) control of PMSM drive without mechanical sensor.

The interesting simulation results obtained on the PMSM show the effectiveness, the convergence and the stability of the proposed control in presence of stator resistance variation, measured noise and load.

Thus in the industrial applications, because of the economic advantages (especially for low-powered motors), one will appreciate very well the experimental implement of this robust EKF sensorless control algorithm to substitute the PMSM mechanical sensor for the reconstitution of the speed, rotor position, load torque and stator resistance.

\section{References}

[1] Dehkordi, A., Gole, A.M. and Maguire, T.L. (2005) PM Synchronous Machine Model for Real-Time Simulation. International Conference on Power Systems Transients, Montreal, Paper No. IPST05-159.

[2] Pillay, P. and Krishnan, R. (1988) Modeling of Permanent Magnet Motor Drives. IEEE Transactions on Industrial Electronics, 35, 537-541. http://dx.doi.org/10.1109/41.9176

[3] Li, J. and Li, Y.Z. (2006) Speed Sensorless Nonlinear Control for PM Synchronous Motor Fed by Three-Level Inverter. IEEE International Conference on Industrial Technology, Mumbai, 15-17 December 2006, 446-451. http://dx.doi.org/10.1109/ICIT.2006.372208

[4] Marino, R., Tomei, P. and Verrelli, C.M. (2006) Nonlinear Adaptive Output Feedback Control of Synchronous Motors with Damping Windings. 32nd Annual Conference on IEEE Industrial Electronics, Paris, 6-10 November 2006, 11311136. http://dx.doi.org/10.1109/IECON.2006.347363

[5] Deng, Z.H. and Nian, X.H. (2015) Robust Control of Permanent Magnet Synchronous Motors. IEEE/CAA Journal of Automatica Sinica, 2, 143-150.

[6] Bingyou, L. (2009) Research on H infinity Robust Tracking Controller for Permanent Magnet Synchronous Motor Servo System. International Conference on Information Engineering and Computer Science, ICIEC, 1-5

[7] Zulkifli, S.A. and Ahmad, M.Z. (2011) Hœ Speed Control for Permanent Magnet Synchronous Motor. 2011 International Conference on Electronic Devices, Systems and Applications (ICEDSA), Kuala Lumpur, 25-27 April 2011, 290293. http://dx.doi.org/10.1109/ICEDSA.2011.5959059

[8] Kalman, R.E. (1960) A New Approach to Linear Filtering and Prediction Problems. Journal of Basic Engineering, 82, 35-45. http://dx.doi.org/10.1115/1.3662552

[9] Gowda, M., Ali, W., Cofie, P. and Fuller, J. (2013) Design and Digital Implementation of Controller for PMSM Using Extended Kalman Filter. Circuits and Systems, 4, 489-497. http://dx.doi.org/10.4236/cs.2013.48064

[10] Taibi, D., Titaouine, A., Benchabane, F. and Bennis, O. (2015) Stability Analysis of the Extended Kalman Filter for Permanent Magnet Synchronous Motor. Journal of Applied Engineering Science \& Technology (JAEST), 1, 51-60

[11] Aissa, A. and Mokhtari, B. (2012) Extended Kalman Filter for Speed Sensorless Direct Torque Control of a PMSM Drive Based Stator Resistance Estimator. Journal of Electrical and Control Engineering, 2, 33-39.

[12] Fateh, B., Titaouine, A., Bennis, O., Guettaf, A., Yahia, K., et al. (2011) Robust Position and Speed Estimation Algorithm for Permanent Magnet Synchronous Drives. European Journal of Scientific Research, 57, 6-14.

[13] Cheol, M., Hyun Nam, K., Jung, M., Chae, C. and Kwon, Y. (2012) Sensorless Speed Control of Permanent Magnet Synchronous Motor Using Unscented Kalman Filter. Proceedings of SICE Annual Conference (SICE), 2018-2023.

[14] Doyle, J.C., Francis, B.A. and Tannenbaum, A.R. (1992) Feedback Control Theory. Maxwell MacMillan International, New York, 240 p.

[15] Lewis, F. (1992) Applied Optimal Control Estimation-Digital Design and Implementation. Prentice Hall, New York, $448 \mathrm{p}$.

[16] De Fornel, B. and Louis, J.P. (2007) Identification and Observation of the Electric Actuators. Hermes, Paris, 250 p.

[17] Leite, V.T., Araujo, R.M. and Freitas, D.R. (2003) A New Online Identification Methodology for Flux and Parameters Estimation of Vector Controlled Induction Motors. IEEE International Electric Machines and Drives Conference, IEMDC'03, 1, 449-455.

[18] Asseu, O., Yeo, Z., Koffi, M., Ori, T.R., Loum, G.L., Zoueu, T.J. and Tanoh, A. (2009) Reduced-Order Sliding Mode Flux Observer and Nonlinear Control of an Induction Motor. Trends in Applied Sciences Research, 4, 14-24. http://dx.doi.org/10.3923/tasr.2009.14.24 


\section{Nomenclature}

$T_{e m}, T_{l}:$ Electromagnetic and load torques (N.m)

$I_{d}, I_{q} \quad:(d, q)$-axis stator currents (A)

$p, J, f \quad: p$ : pole number; $J$ : inertia $\left(\mathrm{kg} \cdot \mathrm{m}^{2}\right)$; $f$ : Damping coefficient $(\mathrm{Nm} \cdot \mathrm{s} / \mathrm{rad})$

$L_{d}, L_{q}:(d, q)$-axis inductances $(\mathrm{H})$

$R_{s}, T_{e}$ : Stator resistance $(\Omega)$ and Sampling period (s).

$V_{d}, V_{q}$ : D-axis and q-axis stator voltage (V).

$\Phi_{f}, \theta \quad: \Phi_{\mathrm{f}}$ : Rotor magnet flux linkage (Wb); $\theta$. Rotor position at electrical angle (rpm).

$\omega_{r}, \Omega \quad: \omega_{r}$ : Rotor electrical radian speed; $\Omega$ : Mechanical rotor speed (rad/s). 